\title{
A VIOLÊNCIA INFANTIL COM DESTAQUE AO ABUSO SEXUAL SOB INTERVENÇÕES PSICANALÍTICAS
}

\section{Child violence with emphasis on sexual abuse under psychoanalytic interventions}

\author{
Thais Pamela Portolani - FAMERP/Brasil \\ Adilia Maria Pires Sciarra - FAMERP/Brasil
}

\begin{abstract}
RESUMO: Ao longo da história da humanidade, crianças e adolescentes tiveram seus direitos violados, sendo vítimas de diversos tipos de violência e experiências de maustratos. Com o tempo, a violência passou a ter maior visibilidade e a Psicanálise vem obtendo resultados significativos diante desta problemática. Objetivou-se investigar e descrever como a abordagem psicanalítica contribui para o acompanhamento eficaz de crianças que sofreram abuso sexual. $\mathrm{O}$ estudo foi delineado pelo método Bibliométrico, o qual se caracteriza por uma técnica quantitativa e estatística que mede os índices de produção e propagação do conhecimento científico. Foram selecionados 17 artigos que resultaram em dados quantitativos acerca do material. Pode-se constatar que a Psicanálise ao abordar o abuso sexual infantil pauta-se em uma ética de cuidados na clínica, a fim de promover e garantir à criança empatia, hospitalidade e escuta, propiciando-lhe um ambiente acolhedor e de confiança, para que a vítima possa reconstruir sua vivência e, sobretudo, ressignificar sua história. A Psicanálise trouxe contribuições relevantes acerca da compreensão do abuso sexual infantil, uma vez que, por meio das suas premissas, destaca pontos essenciais desta abordagem no cuidado à vítima.
\end{abstract}

Palavras-chave: Infância. Violência Infantil. Abuso Sexual. Psicoterapia. Psicanálise.

ABSTRACT: Throughout the history of humankind, children and adolescents have been violated their rights, being victims of various types of violence and experiences of abuse. Over time and in face of some changes, violence has become more visible and Psychoanalysis has been obtaining significant results dealing with this problem. This study aimed to investigate and describe how the psychoanalytical approach contributes to the effective monitoring of children who have been sexually abused. The study was delineated by the Bibliometric method, which is characterized by a quantitative and statistical technique that measures the indices of production and propagation of scientific knowledge. We selected 17 articles that resulted in quantitative data about the material. It can be seen that Psychoanalysis in addressing child sexual abuse is based on an Ethics of care in the clinic, to promote and guarantee the child empathy, hospitality and listening, providing a welcoming and trusting environment, so that the victim can reconstruct his experience and, above all, reframe his story. Psychoanalysis has made relevant contributions about the understanding of child sexual abuse, since, through its premises, it stands out essential points of this approach on victim care.

Keywords: Childhood. Child Violence. Sexual Abuse. Psychotherapy. Psychoanalysis

\section{INTRODUÇÃ̃}

Educação, Psicologia e Interfaces, Volume 4, Número 1, p. 114-126, Janeiro/Março, 2020.

ISSN: 2594-5343. DOI: https://doi.org/10.37444/issn-2594-5343.v4i1.205 
Atualmente, as diversas formas de violência, dentre elas a violência contra crianças e adolescentes, vêm sendo consideradas um grave problema de saúde pública. Embora a violência contra essa população não tenha surgido na contemporaneidade, é na atualidade que as crianças e adolescentes são vistos como sujeitos a partir de seus direitos. O abuso infantil ou violência infantil são os maus-tratos físicos, sexuais, psicológicos ou negligência de uma criança ou adolescente (ARPINI; SIQUEIRA; SAVEGNAGO, 2012).

A violência sexual ocorre quando um adulto, criança ou adolescente maior usam seu poder ou autoridade para envolverem uma criança na atividade sexual. A imaturidade da criança violentada coloca-a na posição de agente capaz de satisfazer os desejos do agressor, reforçando sua posição de objeto e não de sujeito. A violência sexual pode ser física, verbal ou emocional e pode incluir: beijar ou segurar uma criança de maneira sexual; expor uma parte sexual do corpo a uma criança e ter relações sexuais com uma criança com idade inferior a dezesseis anos de idade; falar de maneira sexualmente explícita, entre outros (BRANDÃO; RAMOS, 2010).

Estas experiências são consideradas um importante fator de risco, devido à complexidade do fenômeno e o impacto que a violência sexual causa nas suas vítimas. Com consequências devastadoras, estudos apontam sequelas físicas, psicológicas e cognitivas nas vítimas, que facilitam o desenvolvimento de certas psicopatologias. Crianças e adolescentes que passam por essa experiência de maus-tratos podem desenvolver quadros depressivos, apresentar sinais de enurese, ecoprese, transtornos de ansiedade, hiperatividade, déficit de atenção e transtorno de estresse pós-traumático. (HABIGZANG et al. 2008).

Podem ser observadas alterações comportamentais, tais como: condutas hipersexualizadas, abuso de substâncias, fuga do lar, agressividade, pesadelos, comportamentos autodestrutivos, tentativa de suicídio, isolamento social, dentre outras. Alterações cognitivas são também manifestadas, sendo elas: baixa concentração e atenção, baixo rendimento escolar, desconfiança e sentimentos de inferioridade. As alterações emocionais são expressas por meio de sentimentos de medo, vergonha, culpa, raiva, tristeza e irritabilidade. Ainda pode ocasionar: gravidez, infecções sexualmente 
transmissíveis (ISTs), sintomas físicos, como traumas e hematomas, além de doenças psicossomáticas (HABIGZANG et al. 2008).

\section{MATERIAL E MÉTODO}

Este estudo foi delineado pelo método Bibliométrico, que se caracteriza por uma técnica quantitativa e estatística, a qual busca medir os índices de produção e propagação do conhecimento científico. É uma forma de medir padrões de comunicação escrita e das autorias dessas publicações, quantificando o processo desta comunicação. Os estudos bibliométricos vêm sendo utilizados, para identificar autores e periódicos mais produtivos e paradigmas da ciência (QUEVEDO et al. 2016).

Esta pesquisa está dentro da abordagem quantitativa, a qual consiste em um estudo exploratório e descritivo. O material utilizado neste estudo foi um computador com acesso à Internet e a base de dados para pesquisa. A pesquisa bibliográfica consistiu na busca eletrônica de artigos indexados na base de dados BVS Psicologia Brasil no período de 2000 a 2018, por meio da associação das palavras-chave: psicanálise AND criança AND abuso sexual com o intuito de restringir a pesquisa aos seus respectivos objetivos.

Foram encontrados quarenta e sete resumos, os quais foram lidos respeitando os critérios de inclusão: 1) Veículo de publicação: artigos indexados e de fácil acesso ao pesquisador; 2) Ano de publicação: artigos publicados no período compreendido de 2000 a 2018; 3) Idioma de publicação: artigos publicados em português e inglês. Foram excluídos: dissertações, teses e capítulos de livros; artigos que abordavam populações diferentes da investigação deste estudo, que é a categoria infantil; comorbidades associadas; publicações que apresentavam duplicidade na base; artigos publicados no período anterior a 2000. Após essa seleção, resultaram dezessete artigos que foram analisados sistematicamente.

\section{RESULTADOS E DISCUSSÃO}

Inicialmente, os dezessete artigos foram analisados pela quantidade de autores por cada pesquisa. Observou-se que onze artigos foram de autoria única $(64,70 \%)$; três publicações foram de dupla autoria (17,65\%); e três apresentavam três autores $(17,65 \%)$. A partir desses resultados, pode-se inferir que existe uma concentração de artigos de

Educação, Psicologia e Interfaces, Volume 4, Número 1, p. 114-126, Janeiro/Março, 2020.

ISSN: 2594-5343. DOI: https://doi.org/10.37444/issn-2594-5343.v4i1.205 
autoria individual, o que sugere a ausência de grupos, para a consolidação e o fortalecimento do tema estudado na área.

A avaliação do nome dos autores que possuíam artigos publicados em periódicos é importante, pois assinala um desenvolvimento favorável em relação à área e investimento dos autores no estudo dessa temática. Diante disso, em referência à análise dos nomes dos autores destes artigos, observou-se que nenhum deles se repetiu no número de publicações. Quanto ao número de artigos publicados por ano na área estudada, o ano de 2007 foi o ano que se obteve maior número de artigos com três publicações, seguido dos anos de 2011 a 2013 com dois artigos publicados em cada ano, respectivamente. Entre os anos de 2001 a 2006, 2008 a 2010 e 2016 a 2018 pode-se observar que o número de artigos publicados manteve-se proporcional, sem oscilações, com apenas uma pesquisa em cada ano.

Diante da distribuição dos artigos publicados na área no período de tempo proposto por esta pesquisa (2000 a 2018), e a frequência destas publicações por meio da porcentagem, pode-se concluir que os seguintes anos: 2000, 2003, 2004, 2005, 2012, 2015 e 2017 não apresentaram nenhum artigo publicado. Entre os dezoito anos incluídos para seleção de dados (2000-2018), oito destes anos mantiveram um padrão com apenas um artigo publicado aleatoriamente (5,88\%). Houve um crescimento no ano de 2007 (17,65\%) e nos anos de 2011, 2013 e 2014 (11,77\%).

Referente ao idioma dos dezessete artigos analisados, quinze deles foram encontrados escritos na língua brasileira-portuguesa $(88,23 \%)$, e apenas dois, dos dezessete, estavam em língua inglesa (11,76\%), sendo que um destes artigos foi publicado no ano de 2007 e o outro no ano de 2009. Portanto, torna-se evidente a necessidade de maior investimento dos pesquisadores, especialmente, nas publicações de língua inglesa frente à temática abordada por esta pesquisa.

Todos os artigos analisados trouxeram contribuições relevantes sobre a abordagem psicanalítica no contexto da criança vítima de abuso sexual, portanto, serão expostas suas principais conclusões.

Oliveira e Sei (2014), contextualizam a perspectiva da Teoria Winnicottiana ao ambiente falho, que muitas vezes é encontrado nos casos de abuso sexual infantil. 
Descrever sobre esta temática em Psicanálise requer abordar a importância do meio social ao desenvolvimento emocional da criança e adolescente. $\mathrm{O}$ individuo constitui-se a partir da relação com o outro, principalmente, na relação estabelecida com a mãe, figura que desempenha um papel imprescindível na vida da criança. A mãe identifica-se com o bebê, naturalmente, atendendo as suas necessidades afetivas e fisiológicas, tornando-se uma mãe "suficientemente boa".

Aos poucos, deverá sair desse papel permitindo que o bebê experiencie frustrações e aprenda a tolerá-las, até atingir a independência. Assim, o individuo é capaz de estabelecer o verdadeiro self, por meio de um desenvolvimento sadio, permitindo a integração do ego, a qual estará intimamente relacionada ao ambiente seguro. $\mathrm{O}$ apoio paterno para proteção da mãe e do bebê, à realidade externa, é imprescindível (OLIVEIRA; SEI, 2014).

No entanto, quando este processo é falho o bebê sente-se irreal e tem sua capacidade de simbolização impedida ou fragmentada, reagindo defensivamente ao ambiente com um falso self. Comparando-se esta análise a um contexto de violência, pautado em um ambiente doentio, pode-se pressupor que a criança passa a apresentar dificuldades em sua maturação egóica e em suas relações com o objeto, além da apresentação de características esquizóides e psicóticas, em consequência desta desintegração do ego (OLIVEIRA; SEI, 2014).

O abuso sexual infantil também incide sobre a resolução do Complexo de Édipo, que é parte do desenvolvimento psicossexual da criança e fase estruturante na vida de todo sujeito, onde a criança em seu psiquismo expressa o desejo incestuoso e a rivalidade parental na disputa pelo ser amado e precisa dos pais na marcação dos limites desse desejo. No entanto, quando se trata de uma família incestuosa, o objeto de amor da criança opera dentro da patologia e não aceita as regras impostas pela sociedade, desrespeitando a fragilidade do psiquismo e o corpo da criança (FRANÇA, 2017).

Esse encontro entre as fantasias edípicas da criança e as fantasias pedófilas de um adulto deixam sequelas irreversíveis na vítima, pois a criança terá a certeza de que foram seus desejos edipianos responsáveis por tudo o que aconteceu. E a culpa sentida poderá impedir a criança de liberar sua alegria de viver e sonhar, já na adolescência poderá dificultar a iniciação sexual do jovem. Poderá, ainda, acarretar prejuízos significativos

Educação, Psicologia e Interfaces, Volume 4, Número 1, p. 114-126, Janeiro/Março, 2020.

ISSN: 2594-5343. DOI: https://doi.org/10.37444/issn-2594-5343.v4i1.205 
nas funções psíquicas do sujeito, sendo elas: vigília; juízo; raciocínio; ação controlada, além do entorpecimento dos afetos e a coisificação do corpo. (FRANÇA, 2017).

Outro ponto teórico imprescindível descrito por Oliveira e Sei (2014), que auxilia na compreensão do abuso sexual, constitui-se na concepção da sexualidade infantil retratada na teoria freudiana sobre a existência de uma pulsão sexual desde a infância, atribuindo que a sexualidade nos acompanha desde o nascimento até a morte e, portanto, o sujeito, desde seu nascimento, é dotado de afeto, desejos e conflitos.

Bidaud (2013) pactua das contribuições de Oliveira e Sei (2014) nas quais a sexualidade infantil constitui-se como um dos princípios fundamentais da Psicanálise e acrescenta que a sua constituição trouxe a ideia de uma infância sexuada, a qual gerou escândalo e muita divergência na época. $\mathrm{O}$ autor faz uma crítica à forma como o desfecho do abuso sexual é feito atualmente, sendo ela, a criança, que assume o cenário atual, é a criança passível de ser maltratada, que precisa ser vigiada e protegida da sexualidade do outro e da própria Psicanálise, mantendo a imagem da criança pura, inocente e assexuada. Seria a criança inocente por natureza, diante da perversidade potencial do adulto (BIDAUD, 2013).

O autor ressalta que essa visão, certamente, não exclui a violência que a criança possa ter sofrido de fato, mas que diante disso ela é privada de sua condição de sujeito com processos psíquicos e substituída pelo sexual, tornando-se um objeto a ser explorado, no qual é necessário obter-se uma confissão, e não necessariamente uma palavra dirigida ao outro. A palavra da criança é dissociada do acontecimento, confia-se no evento e a mesma não é escutada em sua história (BIDAUD, 2013).

Piza e Alberti (2014) complementam os escritos de Bidaud e pontuam que as ações de proteção, atualmente, muitas vezes constituem-se como efeitos traumáticos, nas quais a subjetividade da criança é negligenciada em nome da justiça. À Psicanálise interessa a realidade inconsciente, construída psiquicamente e as possíveis implicações dos desejos da criança.

Junior e Ramos (2010) corroboram a pesquisa de Bidaud (2013) e Piza e Alberti (2014) a partir da problematização do sujeito (criança) como constituinte de desejos em toda sua complexidade, inclusive sexual. Ao predeterminar papéis aos integrantes da 
cena, excluímos o sujeito que fixado como vítima, não poderá aparecer como outra coisa. O que diversas abordagens fazem, atualmente, é abolir a história e, consequentemente, o sujeito analisado.

Diante do exposto, é válido ressaltar que, quando tratamos de sexualidade infantil, existe uma grande diferença entre a organização da sexualidade na criança com a sexualidade adulta, sendo a infantil um processo de descobertas, imaturo, polimorfo e inacabado. A criança em decorrência de uma sedução adulta pode ser excitada, prematuramente, excedendo seu controle, gerando efeitos traumáticos à mesma (OLIVEIRA; SEI, 2014).

Ao mencionar efeitos traumáticos, trago o "trauma" como outro elemento primordial à abordagem psicanalítica, quando se trata de abuso sexual infantil. De modo geral, o conceito de trauma caracteriza-se por qualquer estimulação inadequada à metabolização do psiquismo infantil, ou seja, aquilo que a psique é capaz de suportar (OLIVEIRA; SEI, 2014). O trauma reveste-se de comoção psíquica, promovendo destruição, ruína e perda da própria essência, corriqueiro nos casos de abuso infantil (MANDELBAUM; SCRAIBER; OLIVEIRA, 2016).

A teoria freudiana indica que quanto mais insuportável for à realidade objetiva, mais o sujeito se afasta dela, isto é, desmente o evento e recusa a realidade por meio de uma percepção traumatizante. Diante disso, o abuso sofrido pela criança, que se caracteriza por um fato objetivo, torna-se traumático e, assim, impossibilitado de ser processado psiquicamente. A criança imposta nesta realidade insuportável pode ter um excesso de excitação e descarga motora, como a masturbação ou a transformação da realidade, desmentindo o fato ocorrido (CONTE, 2008).

Peláez (2009) se fundamenta nos achados da teoria ferencziana e descreve que a criança não possui mecanismos suficientes para vincular o excesso de excitação que o trauma causa. $\mathrm{O}$ adulto que usa a criança, para suas satisfações sexuais ou emocionais (raiva ou ódio), pega a criança desprevenida e a torna indefesa. A experiência traumática destrói o estado interior da criança e deixa-a insegura diante de si e do mundo. A criança se vê diante de um individuo que despendia seus sentimentos, considerado confiável, mas que agora a coloca em um estado de total impotência. A teoria ferencziana elucida dois momentos do trauma.

Educação, Psicologia e Interfaces, Volume 4, Número 1, p. 114-126, Janeiro/Março, 2020.

ISSN: 2594-5343. DOI: https://doi.org/10.37444/issn-2594-5343.v4i1.205 
. O primeiro momento dar-se-á quando o adulto confunde a linguagem da ternura da criança com a sua própria: a da paixão. A criança, fragilizada, tende a submeterse aos desejos do agressor renegando a si mesma. Com a personalidade frágil, ainda em construção, passa a acreditar que é maldosa e responsável pelo abuso. Atinge um grau de masoquismo excessivo, como se fosse merecedora das piores relações e das experiências mais humilhantes. Já o segundo momento do trauma, é quando qualquer adulto, inclusive o agressor, comporta-se como se nada tivesse acontecido, ignora os pedidos de ajuda da criança, que agora se vê em risco de perder as relações afetivas que possui, a menos que apague o que lhe aconteceu, a partir disso, a criança hesita sobre sua própria percepção e vivência traumática (PERON, 2007).

Kupermann (2011) complementa por meio do modelo clínico desenvolvido por Winnicott e Ferenzczi de que a concepção ferenziana de trauma traduz uma falha ambiental que reproduz o abandono da criança, em um período importante de produção de sentido compartilhado com os adultos. A criança utiliza da clivagem, sendo a maneira que encontra na ausência de figuras protetoras, de desempenhar para si mesma o papel de pai e mãe. A criança amadurece rápido demais, aumenta sua autopercepção e assume a função de cuidado de si, resultante de uma formação defensiva, responsável por um sentimento de inautenticidade.

Outros conceitos básicos da psicanálise, que permeiam a relação da criança com o terapeuta, na clínica, e devem ser considerados no cuidado às vítimas de abuso sexual infantil são: a transferência, a contratransferência e a aliança terapêutica. A transferência consiste em sentimentos, lembranças e comportamentos do passado, que são reeditados na relação paciente e terapeuta; a contratransferência diz respeito às reações inconscientes do terapeuta ao paciente. Ambas devem ser observadas pelo terapeuta, pois podem ser comunicadas pela vítima por meio do brincar, na relação transferencial estabelecida e ou até na aliança terapêutica construída (OLIVEIRA; SEI, 2014).

Terra (2011) descreve sobre o conceito da contratransferência, e alerta o terapeuta ao fato de que o contato com vítimas de abuso sexual gera sentimentos contratransferências em quem as atende, não apenas por estar diante de pessoas com intenso sofrimento psíquico, mas também pelo fato de que situações, como esta, deixam 
clara a fragilidade e impotência do profissional. Observa a necessidade de o terapeuta suportar os sentimentos, os quais são despertados em si próprio, ao invés de os descarregar (como é feito pelo paciente), a fim de os subordinar ao processo analítico; servindo, assim, como espelho ao paciente.

Em casos de suspeita de abuso, a relação terapêutica é essencial, visto que é por meio dela que o trauma será revelado, reestruturado e o self reintegrado. O processo de cura na psicoterapia de vítimas de abuso sexual na infância encontra-se na relação terapêutica, que dá a oportunidade do paciente reviver e ao mesmo tempo ressignificar o dano que lhe foi causado. Portanto, o self do terapeuta é fundamental para o estabelecimento de uma relação clara e aberta na psicoterapia (TERRA, 2011).

Assim sendo, o tratamento psicanalítico, diante do abuso sexual infantil (trauma), apoia-se em princípios norteadores de uma ética de cuidados na clínica, sendo eles: a empatia; a hospitalidade e a saúde do analista para acolher os movimentos espontâneos e agressivos do cliente. A tríade que norteia o tratamento consiste na associação livre; acolhimento à regressão para a dependência e jogo ou brincar compartilhado (KUPERMANN, 2011).

A análise infantil constitui-se como uma medida poderosa no tratamento, auxiliando na liberação, por meio do brincar, de níveis exagerados de angústia e sadismo, os quais podem ser encontrados em crianças expostas a situações traumáticas. Quanto antes se iniciar a intervenção psicoterápica, maiores as chances de elaboração do traumatismo sofrido. O desafio enfrentado pelo tratamento é auxiliar a criança, por meio de sua capacidade lúdica, a liberar a culpa sentida e vivenciada pela fantasia incestuosa. É preciso criar condições, para que o traumatismo encontre vias de conexão com a linguagem (FRANÇA, 2017).

O psicanalista, ao lidar com a criança traumatizada, deve estar disponível, sensivelmente, para sustentar a desintegração deste paciente e oferecer hospitalidade àquele que fala uma língua intraduzível. Tais ações complementam a importância e a necessidade do brincar compartilhado, o qual possibilita, à criança, a elaboração da dor e produção de sentido. Um psicanalista que não pode brincar, não está preparado para desempenhar seu papel (KUPERMANN, 2011).

Educação, Psicologia e Interfaces, Volume 4, Número 1, p. 114-126, Janeiro/Março, 2020. ISSN: 2594-5343. DOI: https://doi.org/10.37444/issn-2594-5343.v4i1.205 
A escuta do sofrimento da criança também se constitui como fator fundamental no trabalho do analista e dá inicio ao processo de elaboração psíquica. A elaboração psíquica consiste em um processo, que permite ao indivíduo adquirir um significante, uma representação, uma fala diante de um fato traumático, como o abuso. Tal processo invade a criança e permite uma transformação da situação violenta em uma representação processada psiquicamente, por meio de recomposição simbólica. $\mathrm{O}$ ato de falar é terapêutico e permite uma recomposição psíquica da criança, mas precisa da escuta analítica (CONTE, 2008).

Medeiros (2013) complementa a importância do processo terapêutico, para auxiliar a criança abusada sexualmente, além da necessidade de aproveitar o espaço como um apoio às suas famílias. Descreve sobre a necessidade de articular o trabalho terapêutico com instituições de cuidado, envolvidas com o fato, e colaborar, assim, para o desenvolvimento emocional da criança e da própria família. Reforça, ainda, a imprescindibilidade de se realizar novos estudos, os quais provoquem discussões, diante do tema, aprofundem o conhecimento e delimitem as estratégias de trabalho.

Portanto, a Psicoterapia de Orientação Psicanalítica poderá ajudar a vítima a lidar com os sentimentos e com a invasão que lhe causou tanto sofrimento (MEDEIROS, 2013). Em consequência disso, enquanto analistas, não podemos fechar os olhos para a realidade interpessoal vivenciada, devemos dar espaço à escuta da criança, pois não sabemos o que se passa entre quatro paredes, devemos ouvir o que não nos está sendo contado e o que nós mesmos não estamos ouvindo (ROSS, 2007).

\section{CONSIDERAÇÕES FINAIS}

O abuso sexual infantil é uma problemática que veio obtendo maior visibilidade com o decorrer do tempo, tornando-se um problema de saúde pública. Possui um impacto devastador na vítima ocasionando prejuízos e sequelas que necessitam de intervenções de profissionais habilitados neste tipo de cuidado. Como vimos, a Psicanálise traz contribuições relevantes acerca da compreensão do abuso sexual infantil, uma vez que, por meio das suas premissas, destaca pontos essenciais desta abordagem no cuidado à vítima - como, por exemplo, a sexualidade infantil e a importância de dar visibilidade e

Educação, Psicologia e Interfaces, Volume 4, Número 1, p. 114-126, Janeiro/Março, 2020.

ISSN: 2594-5343. DOI: https://doi.org/10.37444/issn-2594-5343.v4i1.205 
ofertar "escuta" à criança, permitindo-lhe, assim, ser protagonista de sua história e não a colocar apenas no papel da criança maltratada, como é feito nos dias atuais. Além disso, traz à luz o conceito de trauma, evidenciado na maior parte dos estudos analisados, o qual clarifica a concepção e as consequências que o abuso sexual causa na criança vitimada. Por fim, os estudos fazem pontuações sobre o papel do terapeuta ao lidar com a criança vítima de abuso sexual. O analista deve observar os fenômenos da transferência, contratransferência e da aliança terapêutica e ofertar, por meio do seu self íntegro, a oportunidade para o paciente reviver e expressar seus sentimentos, bons e ruins. $\mathrm{O}$ tratamento psicanalítico, diante da criança vítima de abuso sexual, deve ser norteado por uma ética de cuidados na clínica.O analista deve se mostrar disponível por meio da empatia, hospitalidade, oferecendo, assim, um espaço lúdico e de escuta, onde a criança possa estabelecer confiança para elaborar o fato traumático e dar um novo significado à sua história. Esta pesquisa é relevante para aprimorar a prática de profissionais envolvidos no cuidado com a criança vítima de abuso sexual infantil, porém é necessário destacar que este estudo possui limitações, visto que a análise pautou-se em dezessete artigos selecionados na literatura de forma sistemática, delineado pelo Estudo Bibliométrico, portanto, não esgota todas as teorias, autores e técnicas existentes. Finalmente, fomenta a importância de novos estudos e pesquisas na área, para aprimorar e desenvolver o conhecimento de profissionais que trabalham com esta temática.

\section{REFERÊNCIAS BIBLIOGRÁFICAS}

ARPINI, Dorian Mônica; SIQUEIRA, Aline Cardoso; SAVEGNAGO, Sabrina Dal Ongaro. Trauma psíquico e abuso sexual: o olhar de meninas em situação de vulnerabilidade. Psicologia: teoria e prática, v. 14, n. 2, p. 88-101, 2012. BIDAUD, Eric. O que resta da sexualidade infantil? Estilos da Clinica, v. 18, n. 2, p. 318-326, 2013.

BRANDÃO JUNIOR, Pedro Moacyr Chagas; RAMOS, Patrício Lemos. Abuso sexual: do que se trata? Contribuições da psicanálise à escuta do sujeito. Psicologia clínica, v. 22 , n. 1, p. $71-84,2010$.

DE OLIVEIRA, Martina Daolio; SEI, Maíra Bonafé. Abuso sexual e as contribuições da psicologia no âmbito Judiciário. Barbarói, v. 2, n. 41, p. 4-22, 2014.

DE SOUZA CONTE, Bárbara. Depoimento sem dano: a escuta da psicanálise ou a escuta do direito? Psico, v. 39, n. 2, p. 5, 2008.

Educação, Psicologia e Interfaces, Volume 4, Número 1, p. 114-126, Janeiro/Março, 2020.

ISSN: 2594-5343. DOI: https://doi.org/10.37444/issn-2594-5343.v4i1.205 
FRANÇA, Cassandra Pereira. Um corpo maculado na infância: a necessidade de intervenção precoce dos profissionais de saúde. Pesquisas e Práticas Psicossociais, v. 12, n. 3, p. 1-10, 2017.

GUTIÉRREZ PELÁEZ, Miguel. Trauma theory in Sándor Ferenczi’s writings of 1931 and 1932. The International Journal of Psychoanalysis, v. 90, n. 6, p. 1217-1233, 2009.

HABIGZANG, Luísa Fernanda et al. Avaliação psicológica em casos de abuso sexual na infância e adolescência. Psicologia: Reflexão e Crítica, v. 21, n. 2, p. 338-344, 2008 .

JUNQUEIRA, Maria de Fátima Pinheiro da et al. Violência e abuso sexual infantil: uma proposta clínica. Cad. psicanál.(Rio J., 1982), v. 18, n. 21, p. 209-226, 2002.

KUPERMANN, Daniel. A criança, o infantil e o que o psicanalista (não) sabe. Estilos da Clínica, v. 16, n. 2, p. 324-337, 2011.

MANDELBAUM, Belinda; SCHRAIBER, Lilia Blima; D'OLIVEIRA, Ana Flávia PL. Violência e vida familiar: abordagens psicanalíticas e de gênero. Saúde e Sociedade, v. 25, p. 422-430, 2016.

MEDEIROS, Ana Paula. O abuso sexual infantil e a comunicação terapêutica: um estudo de caso. Pensando familias, v. 17, n. 1, p. 54-62, 2013.

MUNDER ROSS, John. Trauma and abuse in the case of Little Hans: A contemporary perspective. Journal of the American Psychoanalytic Association, v. 55, n. 3, p. 779797, 2007.

PERÓN, Paula Regina. Considerações teóricas ferenczianas sobre o trauma. Psicologia revista, v. 16, n. 1/2, p. 13-27, 2007.

PIZA, Luciana; ALBERTI, Sonia. A criança como sujeito e como objeto entre duas formas de investigação do abuso sexual. Psicologia Clínica, v. 26, n. 2, p. 63-85, 2014.

QUEVEDO-SILVA, Filipe et al. Estudo bibliométrico: orientações sobre sua aplicação. Revista Brasileira de Marketing, v. 15, n. 2, p. 246-262, 2016.

TERRA, Luciana. Suspeita de abuso sexual: Um caso de psicoterapia de uma criança de cinco anos. Rev. bras. psicoter, v. 13, n. 2, p. 133-145, 2011.

\section{Credenciais dos autores}

Educação, Psicologia e Interfaces, Volume 4, Número 1, p. 114-126, Janeiro/Março, 2020.

ISSN: 2594-5343. DOI: https://doi.org/10.37444/issn-2594-5343.v4i1.205 
PORTOLANI, Thais Pamela.Graduada em Psicologia (UNIARA), Mestre em Psicologia da Saúde (FAMERP). E-mail: thaisportolani.tpp@gmail.com

SCIARRA, Adília Maria Pires. Doutora em Ciências da Saúde, FAMERP, São José do rio Preto, São Paulo. Auxiliar de Ensino da Faculdade de Medicina de São José do Rio Preto/ Brasil. E-mail: adilia@famerp.br

Endereço para correspondência: Thaís Pamela Portolani. Rua Osvaldo Bertuso, 229, Conj. Habitacional Nadalleto Mazer, Sertãozinho, SP. CEP: 14177-082 E-mail: thaisportolani.tpp@gmail.com

Como citar este artigo (Formato ABNT): PORTOLANI, Thais Pamela; SCIARRA, Adilia Maria Pires. A violência infantil com destaque ao abuso sexual sob intervenções psicanalíticas. Educação, Psicologia e Interfaces, v. 4, n.1, p. 114-126, 2020. DOI: https://doi.org/10.37444/issn-2594-5343.v4i1.205

Recebido: $17 / 11 / 2019$

Aceito: 29/12/2019. 